\title{
$f$-Contractive multivalued maps and coincidence points
}

Marwan A Kutbi*

\section{"Correspondence:}

mkutbi@yahoo.com

Department of Mathematics, King

Abdulaziz University, P.O. Box 80203

Jeddah, 21589, Saudi Arabia

\section{Abstract}

In this paper, we prove a result on the existence of an $f$-orbit for generalized $f$-contractive multivalued maps. Then, we establish main results on the existence of coincidence points and common fixed points for generalized $f$-contractive maps not involving the extended Hausdorff metric and the continuity condition. Our results either generalize or improve a number of metric fixed point results.

MSC: $47 \mathrm{H} 10 ; 47 \mathrm{H} 09 ; 54 \mathrm{H} 25$

Keywords: metric space; fixed point; multivalued contractive map; coincidence point

\section{Introduction}

Let $(X, d)$ be a metric space. Let $2^{X}, \mathrm{Cl}(X)$ and $\mathrm{CB}(X)$ denote the collection of nonempty subsets of $X$, nonempty closed subsets of $X$, and nonempty closed bounded subsets of $X$, respectively. Let $H$ be the Hausdorff metric with respect to $d$, that is,

$$
H(A, B)=\max \left\{\sup _{x \in A} d(x, B), \sup _{y \in B} d(y, A)\right\}
$$

for every $A, B \in \mathrm{CB}(X)$, where $d(x, B)=\inf _{y \in B} d(x, y)$.

Let $f: X \rightarrow X$ be a single-valued map, and let $T: X \rightarrow 2^{X}$ be a multivalued map. A point $x \in X$ is called a fixed point of $T$ if $x \in T(x)$, and the set of fixed points of $T$ is denoted by $\operatorname{Fix}(T)$. A point $x \in X$ is called a coincidence point of $f$ and $T$ if $f(x) \in T(x)$. We denote by $C(f \cap T)$ the set of coincidence points of $f$ and $T$.

We say a sequence $\left\{x_{n}\right\}$ in $X$ is an $f$-orbit of $T$ at $x_{0} \in X$ if $f x_{n} \in T x_{n-1}$ for all $n \geq 1$. We say that $f$ and $T$ weakly commute if $f T x \subset T f x$ for all $x \in X$. Clearly, commuting maps $f$ and $T$ weakly commute.

A multivalued map $T: X \rightarrow \mathrm{CB}(X)$ is called

(i) contraction [1] if for a fixed constant $\lambda \in(0,1)$ and for each $x, y \in X$,

$$
H(T(x), T(y)) \leq \lambda d(x, y) .
$$

(ii) $f$-contraction [2] if for a fixed constant $\lambda \in(0,1)$ and for each $x, y \in X$,

$$
H(T(x), T(y)) \leq \lambda d(f(x), f(y))
$$


Using the concept of Hausdorff metric, Nadler [1] established the following fixed point result for multivalued contraction maps, which in turn is a generalization of the wellknown Banach contraction principle.

Theorem 1.1 [1] Let $(X, d)$ be a complete metric space, and let $T: X \rightarrow \mathrm{CB}(X)$ be a contraction map. Then $\operatorname{Fix}(T) \neq \emptyset$.

This result has been generalized in many directions. Kaneko [2] extended the corresponding results of Jungck [3], Nadler [1] and others as follows.

Theorem 1.2 [2] Let $(X, d)$ be a complete metric space, and let $T: X \rightarrow \mathrm{CB}(X)$ be a multivalued $f$-contraction map which commutes with a continuous map $f$. Then $C(f \cap T) \neq \emptyset$.

This result has been generalized in different directions. For example, see [4-10].

On the other hand, Kada et al. [11] introduced the concept of $w$-distance on a metric space as follows:

Let $(X, d)$ be a metric space. A function $\omega: X \times X \rightarrow[0, \infty)$ is called a $w$-distance on $X$ if it satisfies the following for each $x, y, z \in X$ :

$\left(w_{1}\right) \quad \omega(x, z) \leq \omega(x, y)+\omega(y, z)$

$\left(w_{2}\right)$ a map $\omega(x, \cdot): X \rightarrow[0, \infty)$ is lower semicontinuous;

$\left(w_{3}\right)$ for any $\epsilon>0$, there exists $\delta>0$ such that $\omega(z, x) \leq \delta$ and $\omega(z, y) \leq \delta$ imply $d(x, y) \leq \epsilon$.

Note that, in general, for $x, y \in X, \omega(x, y) \neq \omega(y, x)$ and not either of the implications $\omega(x, y)=0 \Leftrightarrow x=y$ necessarily hold. We say the $w$-distance $\omega$ on $X$ is a $w_{0}$-distance if $x=y$ implies $\omega(x, y)=0$. Clearly, the metric $d$ is a $w$-distance on $X$. Let $(Y,\|\cdot\|)$ be a normed space. Then the functions $\omega_{1}, \omega_{2}: Y \times Y \rightarrow[0, \infty)$ defined by $\omega_{1}(x, y)=\|y\|$ and $\omega_{2}(x, y)=$ $\|x\|+\|y\|$ for all $x, y \in Y$ are $w$-distances [11]. Many other examples and properties of the $w$-distance can be found in $[11,12]$.

The following useful lemma concerning a $w$-distance is given in [11].

Lemma 1.1 [11] Let $(X, d)$ be a metric space, and let $\omega$ be a w-distance on $X$. Let $\left\{x_{n}\right\}$ and $\left\{y_{n}\right\}$ be sequences in $X$, and let $\left\{\alpha_{n}\right\}$ and $\left\{\beta_{n}\right\}$ be sequences in $[0, \infty)$ converging to zero. Then, for the $w$-distance $\omega$ on $X$, the following hold for every $x, y, z \in X$ :

(a) if $\omega\left(x_{n}, y\right) \leq \alpha_{n}$ and $\omega\left(x_{n}, z\right) \leq \beta_{n}$ for any $n \in \mathbb{N}$, then $y=z$; in particular, if $\omega(x, y)=0$ and $\omega(x, z)=0$, then $y=z$;

(b) if $\omega\left(x_{n}, y_{n}\right) \leq \alpha_{n}$ and $\omega\left(x_{n}, z\right) \leq \beta_{n}$ for any $n \in \mathbb{N}$, then $\left\{y_{n}\right\}$ converges to $z$;

(c) if $\omega\left(x_{n}, x_{m}\right) \leq \alpha_{n}$ for any $n, m \in \mathbb{N}$ with $m>n$, then $\left\{x_{n}\right\}$ is a Cauchy sequence;

(d) if $\omega\left(y, x_{n}\right) \leq \alpha_{n}$ for any $n \in \mathbb{N}$, then $\left\{x_{n}\right\}$ is a Cauchy sequence.

For $x \in X$ and $A \in 2^{X}$, we denote, $\omega(x, A)=\inf _{y \in A} \omega(x, y)$. Now, let $T: X \rightarrow \mathrm{Cl}(X)$ be a multivalued map, and let $f: X \rightarrow X$ be a single-valued map. We say

(iii) $T$ is $w$-contractive [12] if there exist a $w$-distance $\omega$ on $X$ and $\lambda \in(0,1)$ such that for any $x, y \in X$ and $u \in T(x)$, there is $v \in T(y)$ with

$$
\omega(u, v) \leq \lambda \omega(x, y)
$$


(iv) $T$ is generalized $f$-contractive if there exist a $w_{0}$-distance $\omega$ on $X$ and $\lambda \in(0,1)$ such that for any $x, y \in X, u \in T(x)$, there is $v \in T(y)$ with

$$
\omega(u, v) \leq \lambda M_{f}(x, y)
$$

where

$$
\begin{aligned}
M_{f}(x, y)= & \max \{\omega(f(x), f(y)), \omega(f(x), T(x)), \omega(f(y), T(y)), \\
& \left.\frac{1}{2}[\omega(f(x), T(y))+\omega(f(y), T(x))]\right\} .
\end{aligned}
$$

Using the concept of $w$-distance, Suzuki and Takahashi [12] improved Nadler's fixed point result as follows.

Theorem 1.3 Let $(X, d)$ be a complete metric space. Then for each $w$-contractive map $T$ : $X \rightarrow \mathrm{Cl}(X)$, the set $\operatorname{Fix}(T) \neq \emptyset$.

This result has been generalized by many authors, for example, see [13-16]. In this paper, first we establish a lemma with respect to a $w$-distance, which is an improved version of the lemma given in [3], and then we prove a key lemma on the existence of an $f$-orbit for generalized $f$-contractive maps. Finally, we present our main results on the existence of coincidence points and common fixed points for generalized $f$-contractive maps not involving the extended Hausdorff metric. As a consequence, we obtain a fixed point result. Our results either generalize or improve a number of known results.

\section{Results}

Using the concept of $w$-distance, first we improve a corresponding result of Jungck [3] as follows.

Lemma 2.1 Let $(X, d)$ be a complete metric space with a $w$-distance $\omega$. If there exist a sequence $\left\{x_{n}\right\}$ in $X$ and a constant $\lambda, 0<\lambda<1$, such that for all $n \in \mathbb{N}$,

$$
\omega\left(x_{n}, x_{n+1}\right) \leq \lambda \omega\left(x_{n-1}, x_{n}\right)
$$

then the sequence $\left\{x_{n}\right\}$ converges in $X$.

Proof It is enough to show that $\left\{x_{n}\right\}$ is a Cauchy sequence in $X$. Note that for each $n \in \mathbb{N}$, we have

$$
\begin{aligned}
\omega\left(x_{n}, x_{n+1}\right) & \leq \lambda \omega\left(x_{n-1}, x_{n}\right) \\
& \leq \lambda^{2} \omega\left(x_{n-2}, x_{n-1}\right) \\
& \vdots \\
& \leq \lambda^{n} \omega\left(x_{0}, x_{1}\right) .
\end{aligned}
$$


Thus

$$
\omega\left(x_{n}, x_{n+1}\right) \leq \lambda^{n} \omega\left(x_{0}, x_{1}\right) .
$$

Consequently, for $m \geq n$, we get

$$
\begin{aligned}
\omega\left(x_{n}, x_{m}\right) & \leq \omega\left(x_{n}, x_{n+1}\right)+\omega\left(x_{n+1}, x_{n+2}\right)+\cdots+\omega\left(x_{m-1}, x_{m}\right) \\
& \leq \lambda^{n} \omega\left(x_{0}, x_{1}\right)+\lambda^{n+1} \omega\left(x_{0}, x_{1}\right)+\cdots+\lambda^{m-1} \omega\left(x_{0}, x_{1}\right),
\end{aligned}
$$

and thus

$$
\omega\left(x_{n}, x_{m}\right) \leq \frac{\lambda^{n}}{1-\lambda} \omega\left(x_{0}, x_{1}\right) .
$$

Since $0<\lambda<1$, we have $\lambda^{n} \rightarrow 0$ as $n \rightarrow \infty$. And thus by Lemma 1.1, $\left\{x_{n}\right\}$ is a Cauchy sequence in $X$. Since $X$ is complete, the sequence $\left\{x_{n}\right\}$ converges to a point in $X$.

The following lemma is crucial for our main results.

Lemma 2.2 Let $(X, d)$ be a complete metric space, and let $T: X \rightarrow \mathrm{Cl}(X)$ be a generalized $f$-contractive map such that $T(X) \subset f(X)$. Then there exists an $f$-orbit $\left\{x_{n}\right\}$ of $T$ at $x_{0} \in X$ such that $\left\{f\left(x_{n}\right)\right\}$ converges in $X$.

Proof Let $x_{0} \in X$ and choose $y_{0} \in T\left(x_{0}\right)$. Since $T\left(x_{0}\right) \subset f(X)$, then there exists $x_{1} \in X$ such that $f\left(x_{1}\right)=y_{0} \in T\left(x_{0}\right)$, and thus, by the definition of $T$, there exists $y_{1} \in T\left(x_{1}\right)$ such that

$$
\omega\left(f\left(x_{1}\right), y_{1}\right) \leq \lambda M_{f}\left(x_{0}, x_{1}\right)
$$

where $0<\lambda<1$. Since $T\left(x_{1}\right) \subset f(X)$, there exists $x_{2} \in X$ such that $f\left(x_{2}\right)=y_{1} \in T\left(x_{1}\right)$. Thus

$$
\omega\left(f\left(x_{1}\right), f\left(x_{2}\right)\right) \leq \lambda M_{f}\left(x_{0}, x_{1}\right)
$$

Similarly, using the definition of $T$ and the fact that $T(X) \subset f(X)$, there exists $x_{3} \in X$ such that $f\left(x_{3}\right) \in T\left(x_{2}\right)$ and

$$
\omega\left(f\left(x_{2}\right), f\left(x_{3}\right)\right) \leq \lambda M_{f}\left(x_{1}, x_{2}\right) .
$$

Continuing this process, we get a sequence $\left\{x_{n}\right\}$ in $X$ such that for all $n, f\left(x_{n+1}\right) \in T\left(x_{n}\right)$ and

$$
\omega\left(f\left(x_{n}\right), f\left(x_{n+1}\right)\right) \leq \lambda M_{f}\left(x_{n-1}, x_{n}\right),
$$

that is,

$$
\begin{aligned}
\omega\left(f\left(x_{n}\right), f\left(x_{n+1}\right)\right) \leq & \lambda \max \left\{\omega\left(f\left(x_{n-1}\right), f\left(x_{n}\right)\right), \omega\left(f\left(x_{n-1}\right), T\left(x_{n-1}\right)\right), \omega\left(f\left(x_{n}\right), T\left(x_{n}\right)\right),\right. \\
& \left.\frac{1}{2}\left[\omega\left(f\left(x_{n-1}\right), T\left(x_{n}\right)\right)+\omega\left(f\left(x_{n}\right), T\left(x_{n-1}\right)\right)\right]\right\} .
\end{aligned}
$$


Note that

$$
\begin{aligned}
\omega\left(f\left(x_{n}\right), f\left(x_{n+1}\right)\right) \leq & \lambda \max \left\{\omega\left(f\left(x_{n-1}\right), f\left(x_{n}\right)\right), \omega\left(f\left(x_{n-1}\right), f\left(x_{n}\right)\right), \omega\left(f\left(x_{n}\right), f\left(x_{n+1}\right)\right),\right. \\
& \left.\frac{1}{2}\left[\omega\left(f\left(x_{n-1}\right), f\left(x_{n+1}\right)\right)+\omega\left(f\left(x_{n}\right), f\left(x_{n}\right)\right)\right]\right\} \\
= & \lambda \max \left\{\omega\left(f\left(x_{n-1}\right), f\left(x_{n}\right)\right), \omega\left(f\left(x_{n}\right), f\left(x_{n+1}\right)\right), \frac{1}{2}\left[\omega\left(f\left(x_{n-1}\right), f\left(x_{n+1}\right)\right)\right]\right\},
\end{aligned}
$$

and we get

$$
\omega\left(f\left(x_{n}\right), f\left(x_{n+1}\right)\right) \leq \lambda \max \left\{\omega\left(f\left(x_{n-1}\right), f\left(x_{n}\right)\right), \frac{1}{2}\left[\omega\left(f\left(x_{n-1}\right), f\left(x_{n+1}\right)\right)\right]\right\} .
$$

Also, note that

$$
\begin{aligned}
\omega\left(f\left(x_{n}\right), f\left(x_{n+1}\right)\right) & \leq \lambda \max \left\{\omega\left(f\left(x_{n-1}\right), f\left(x_{n}\right)\right), \frac{1}{2}\left[\omega\left(f\left(x_{n-1}\right), f\left(x_{n}\right)\right)+\omega\left(f\left(x_{n}\right), f\left(x_{n+1}\right)\right)\right]\right\} \\
& \leq \lambda \max \left\{\left[\omega\left(f\left(x_{n-1}\right), f\left(x_{n}\right)\right), \omega\left(f\left(x_{n}\right), f\left(x_{n+1}\right)\right)\right]\right\} .
\end{aligned}
$$

Thus, for each $n \in \mathbb{N}$, we get

$$
\omega\left(f\left(x_{n}\right), f\left(x_{n+1}\right)\right) \leq \lambda \omega\left(f\left(x_{n-1}\right), f\left(x_{n}\right)\right) .
$$

Since the sequence $\left\{f\left(x_{n}\right)\right\}$ is in the complete metric space $X$ satisfying the inequality (1), it follows from Lemma 2.1 that $\left\{f\left(x_{n}\right)\right\}$ converges in $X$.

Remark 2.1 Since for each $n \in \mathbb{N}$ we have

$$
\omega\left(f\left(x_{n}\right), f\left(x_{n+1}\right)\right) \leq \lambda \omega\left(f\left(x_{n-1}\right), f\left(x_{n}\right)\right),
$$

following the proof of Lemma 2.1, we obtain the following two useful inequalities.

$$
\omega\left(f\left(x_{n}\right), f\left(x_{n+1}\right)\right) \leq \lambda^{n} \omega\left(f\left(x_{0}\right), f\left(x_{1}\right)\right)
$$

and for $m \geq n$

$$
\omega\left(f\left(x_{n}\right), f\left(x_{m}\right)\right) \leq \frac{\lambda^{n}}{1-\lambda} \omega\left(f\left(x_{0}\right), f\left(x_{1}\right)\right) .
$$

Without using the extended Hausdorff metric and continuity conditions, we prove a coincidence result which improves many known results including Theorem 1.2 due to [2], Theorem 3.3 in [17] and Theorem 2 in [7].

Theorem 2.1 Suppose that all the hypotheses of Lemma 2.2 hold. Furthermore, iffor every $y \in X$ with $f(y) \notin T(y)$

$$
\inf \{\omega(f(x), y)+\omega(f(x), T(x)): x \in X\}>0 .
$$

Then $C(f \cap T) \neq \emptyset$. 
Proof By Lemma 2.2, there exists an $f$-orbit $\left\{x_{n}\right\}$ of $T$ at $x_{0} \in X$ such that $\left\{f\left(x_{n}\right)\right\}$ converges in $X$. Also note that for each $n \in \mathbb{N}$, we have

$$
\omega\left(f\left(x_{n}\right), f\left(x_{n+1}\right)\right) \leq \lambda \omega\left(f\left(x_{n-1}\right), f\left(x_{n}\right)\right),
$$

where $0<\lambda<1$. Let $f\left(x_{n}\right) \rightarrow y \in X$. Now since $\omega\left(f\left(x_{n}\right), \cdot\right)$ is lower semicontinuous, from Remark 2.1 (2), we have

$$
\begin{aligned}
\omega\left(f\left(x_{n}\right), y\right) & \leq \lim _{m \rightarrow \infty} \inf \omega\left(f\left(x_{n}\right), f\left(x_{m}\right)\right) \\
& \leq \frac{\lambda^{n}}{1-\lambda} \omega\left(f\left(x_{0}\right), f\left(x_{1}\right)\right) .
\end{aligned}
$$

Since $\lambda<1$, we get $\omega\left(f\left(x_{n}\right), y\right) \rightarrow 0$ as $n \rightarrow \infty$. Assume that $f(y) \notin T(y)$, then from the hypothesis and Remark 2.1, we get

$$
\begin{aligned}
0 & <\inf \{\omega(f(x), y)+\omega(f(x), T(x)): x \in X\} \\
& \leq \inf \left\{\omega\left(f\left(x_{n}\right), y\right)+\omega\left(f\left(x_{n}\right), T\left(x_{n}\right)\right): n \in \mathbb{N}\right\} \\
& \leq \inf \left\{\omega\left(f\left(x_{n}\right), y\right)+\omega\left(f\left(x_{n}\right), f\left(x_{n+1}\right)\right): n \in \mathbb{N}\right\} \\
& \leq \inf \left\{\frac{\lambda^{n}}{1-\lambda} \omega\left(f\left(x_{0}\right), f\left(x_{1}\right)\right)+\lambda^{n} \omega\left(f\left(x_{0}\right), f\left(x_{1}\right)\right): n \in \mathbb{N}\right\} \\
& =\left\{\frac{2-\lambda}{1-\lambda}\right\} \omega\left(f\left(x_{0}\right), f\left(x_{1}\right)\right) \inf \left\{\lambda^{n}: n \in \mathbb{N}\right\}=0,
\end{aligned}
$$

which is impossible, and thus $f(y) \in T(y)$, that is, $y$ is a coincidence point of $f$ and $T$.

If we take $f=I$ (an identity map on $X$ ) in Theorem 2.1, we obtain the following improved version of the corresponding fixed point results in $[12,17,18]$.

Corollary 2.1 Let $(X, d)$ be a complete metric space, let $\omega$ be a $w$-distance on $X$, and let $T: X \rightarrow \mathrm{Cl}(X)$ be a multivalued map satisfying the following:

(I) for fixed $\lambda \in(0,1)$, for each $x, y \in X$ and $u \in T(x)$, there exists $v \in T(y)$ such that

$$
\omega(u, v) \leq \lambda M_{\omega}(x, y)
$$

where

$$
M_{\omega}(x, y)=\max \left\{\omega(x, y), \omega(x, T(x)), \omega(y, T(y)), \frac{1}{2}[\omega(x, T(y))+\omega(y, T(x))]\right\},
$$

(II) $\inf \{\omega(x, y)+\omega(x, T(x)): x \in X\}>0$.

Then $\operatorname{Fix}(T) \neq \emptyset$.

Finally, we obtain a common fixed point result.

Theorem 2.2 Suppose that all the hypotheses of Theorem 2.1 hold. Further, if the maps $f$ and $T$ commute weakly and satisfy the condition that $f(x) \neq f^{2}(x)$, which implies $f(x) \notin$ $T(x)$, then $f$ and $T$ have a common fixed point. 
Proof From Theorem 2.1 we have $f(y) \in T(y)$, and thus we get $f(y)=f^{2}(y)$. Note that

$$
f(y)=f(f(y)) \in f(T(y)) \subseteq T(f(y)),
$$

that is, $f(y)$ is a fixed point of $T$. Also note that $f(y)$ is a fixed point of $f$ and thus $f(y)$ is a common fixed point of $T$ and $f$.

\section{Competing interests}

The author declares that he has no competing interests.

\section{Acknowledgements}

This paper is funded by the Deanship of Scientific Research (DSR), King Abdulaziz University, Jeddah, under grant No. 491/130/1432. The author therefore acknowledges with thanks DSR for technical and financial support.

\section{Received: 2 October 2012 Accepted: 13 March 2013 Published: 2 April 2013}

\section{References}

1. Nadler, SB: Multivalued contraction mappings. Pac. J. Math. 30, 475-488 (1969)

2. Kaneko, H: Single-valued and multivalued $f$-contractions. Boll. Unione Mat. Ital. 6, 29-33 (1985)

3. Jungck, G: Commuting mappings and fixed points. Am. Math. Mon. 83, 261-263 (1976)

4. Abbas, M, Hussain, $\mathrm{N}$, Rhoades, BE: Coincidence point theorems for multivalued $f$-weak contraction mappings and applications. Rev. R. Acad. Cienc. Exactas Fís. Nat., Ser. a Mat. (Ed. Impr.) 105(2), 261-272 (2011). doi:10.1007/s13398-011-0036-4

5. Daffer, PZ, Kaneko, H: Multivalued f-contractive mappings. Boll. Unione Mat. Ital. 8-A(7), $233-241$ (1994)

6. Hussain, N, Alotaibi, A: Coupled coincidences for multi-valued nonlinear contractions in partially ordered metric spaces. Fixed Point Theory Appl. 2011, 81 (2011) (18 November 2011)

7. Kaneko, H, Sessa, S: Fixed point theorems for compatible multi-valued and single-valued mappings. Int. J. Math. Math. Sci. 12(2), 257-262 (1989)

8. Latif, A, Tweddle, I: Some results on coincidence points. Bull. Aust. Math. Soc. 59, 111-117 (1999)

9. Pathak, HK: Fixed point theorems for weak compatible multivalued and single-valued mappings. Acta Math. Hung. 67(1-2), 69-78 (1995)

10. Pathak, HK, Khan, MS: Fixed and coincidence points of hybrid mappings. Arch. Math. 3, 201-208 (2002)

11. Kada, O, Susuki, T, Takahashi, W: Nonconvex minimization theorems and fixed point theorems in complete metric spaces. Math. Jpn. 44, 381-391 (1996)

12. Suzuki, T, Takahashi, W: Fixed point theorems and characterizations of metric completeness. Topol. Methods Nonlinear Anal. 8, 371-382 (1996)

13. Bin Dehaish, BA, Latif, A: Fixed point results for multivalued contractive maps. Fixed Point Theory Appl. 2012,61 (2012)

14. Latif, A, Abdou, AAN: Fixed points of generalized contractive maps. Fixed Point Theory Appl. 2009, Article ID 487161 (2009). doi:10.1155/2009/487161

15. Latif, A, Abdou, AAN: Multivalued generalized nonlinear contractive maps and fixed points. Nonlinear Anal. 74, 1436-1444 (2011)

16. Suzuki, T: Generalized distance and existence theorems in complete metric spaces. J. Math. Anal. Appl. 253, 440-458 (2001)

17. Daffer, PZ, Kaneko, H: Fixed points generalized contractive multi-valued mappings. J. Math. Anal. Appl. 192, 655-666 (1995)

18. Kaneko, H: A general principle for fixed points of contractive multivalued mappings. Math. Jpn. 31(3), 407-422 (1986)

doi:10.1186/1029-242X-2013-141

Cite this article as: Kutbi: $f$-Contractive multivalued maps and coincidence points. Journal of Inequalities and Applications 2013 2013:141. 